\title{
El mundo laboral de las mujeres en la microempresa
}

\author{
Julia Evelin Martinez
}

\section{Resumen}

Este artículo expone la situación de desigualdad que enfrenta la mujer en el sector informal como propietaria o empleada de unidades económicas microempresariales. Este hecho trae consigo graves implicaciones en términos de equidad y posibilidades reales para el desarrollo socioeconómico del país, lo cual se evidencia en un ingreso mensual promedio menor que el del hombre que realiza la misma actividad; menor cobertura al sistema de seguridad social; la doble jornada de trabajo, ya que también tiene que realizar labores de domesticidad, etc. Por tanto, hace una reflexión sobre el futuro del sector informal dentro de la economía neoliberal salvadoreña y enfatiza la necesidad de incorporar, dentro de este sector, un enfoque de género.

\section{Introducción}

Comúnmente, la temática de derechos de la mujer trabajadora tiende a circunscribirse a la esfera de las relaciones laborales que se establecen dentro de las unidades económicas del llamado sector formal de la economía y, por lo tanto, las estadísticas utilizadas para abordar este tema por lo general hacen referencia a los establecimientos de más de diez trabajadores, registrados oficialmente y a problemáticas ligadas a las particularidades de este tipo de empresas en el país: desigualdad en los salarios, desigualdad en el acceso a puestos de trabajo de mayor responsabilidad, desigualdad en la participación en organizaciones sindicales, entre otras muchas otras formas de dis- 
criminación. Sin embargo, muy poco o nada se ha logrado avanzar en la investigación de la situación de la mujer ocupada en el sector informal urbano, $y$, en consecuencia, debe reconocerse que nuestra visión del mundo laboral femenino en El Salvador es aún bastante limitado.

La importancia cuantitativa que las ocupaciones del sector informal tienen dentro del mercado laboral salvadoreño justifican la necesidad no sólo de hacer un esfuerzo por conocer mejor la problemática laboral más específica que caracteriza a este sector, sino también para incorporar dentro de la política laboral una consideración especial hacia las mujeres que laboran en él, quienes son víctimas de la doble discriminación que significa ser mujeres laborando dentro de un sector subordinado a las necesidades y la lógica de acumulación del capital de las empresas del sector formal.

Para abordar este tema, el presente artículo, a partir de la categoría microempresa, describe la situación de discriminación que afecta a la mujer en el sector informal como propietarias o como empleadas de unidades económicas microempresariales, seguido de un análisis de los principales determinantes que condicionan la situación de la mujer trabajadora en este sector. El trabajo concluye con una reflexión sobre el futuro del sector informal de cara a la profundización del proceso de reformas económicas neoliberales que experimenta la economía salvadoreña y sobre la necesidad de poner en práctica una política laboral que tome en consideración también la realidad laboral dentro de este sector y que incorpore un enfoque de género en su diseño e implementación.

\section{Sobre la utilización de la categorías sector informal y microempresa}

Para efectos de este trabajo se utiliza la categoría de microempresa como sinónimo de actividades del sector informal popular urbano, aun cuando se reconoce que conceptualmente presentan diferencias sustanciales y que su utilización varra de acuerdo con el enfoque ideológico y político que desea privilegiar un determinado autor o institución.

En todo caso, vale la pena aclarar que nuestro interés se centra fundamentalmente en aquel sector de la economía salvadoreña integrado por pequeñas unidades de producción y distribución de bienes y servicios, situadas en las zonas urbanas, y que pertenecen a productores (as) independientes y a trabajadores (as) por cuenta propia, que a veces emplean a miembros de la familia o algunos asalariados (as) o aprendices. Sus principales características son su escasa o nula disponibilidad de capital, la utilización de técnicas rudimentarias, el uso de mano de obra con bajo nivel de calificación, sus bajos niveles de productividad y la generación de ingresos muy bajos, irregulares e inestables, tanto para los propietarios (as) como para los empleados (as).

Las unidades económicas ubicadas en este sector funcionan de acuerdo a una lógica económica fundamentada en la satisfacción de las necesidades de reproducción de sus miembros y no en la búsqueda de ganancias y en la acumulación de capital, que sería el rasgo más diferenciador en relación con el sector capitalista de la economía, comúnmente conocido como sector formal.

Es necesario también aclarar que el término microempresa, a diferencia del término sector informal, es utilizado en nuestro medio más desde un interés cuantitativo que explicativo, sobre todo para facilitar la recolección de información sobre las unidades económicas (capitalistas y no capitalistas) que emplean entre uno y diez trabajadores (as), incluyendo al propietario (a) y cuyas ventas anuales son inferiores a los 600,000 colones. 1

Históricamente, los esfuerzos de cuantificación del sector de la microempresa y el uso de esa categoría han estado fuertemente asociados a la necesidad de los gobiernos de separarlo de las pequeñas empresas con miras a la aplicación de incentivos económicos, específicamente crediticios. Sin embargo, a partir de la década de los ochenta se ha tendido a la utilización generalizada del término

1. Véase varios autores, Libro blanco de la microempresa, p. 4. 
microempresa como sinónimo del sector informal, por parte de los agentes públicos y privados vinculados a esta temática. Algunos de ellos inclusive han llegado a hablar de microempresas del sector informal., con lo que han contribuido a generar inayor confusión sobre el tema.

Conscientes de los riesgos que conlleva el uso indistinto de las categorías que aquí se proponen, es preciso recurrir a este artificio con el fin de uprovechar la información estadística más recienle, confiada en que las diferencias a favor y en contra que pueda generar la utilización del mismo, terminen por compensarse mutuamente.

\section{La realidad del trabajo de la mujer en la microempresa}

Se estima que a nivel nacional existe un total de 397,000 microempresas que dan ocupación a unas 603,340 personas, entre empleadores y empleadoras, autoempleados (as) y trabajadores (as). En su conjunto aportan a la formación del Producto Interno Bruto (PIB) entre un 24 y un 36 por ciento. 2

La situación de la mujer ocupada en la microempresa, a nuestro juicio, debe ser enfocada a partir de las dos posiciones que desempeña dentro de este sector, es decir, como propietaria de una microempresa o bien como empleada en una microempresa. Establecer esta separación es muy difícil, pues en la mayoría de los casos las mujeres al mismo tiempo que propietarias de una microempresa son las únicas empleadas en ellas. No obstante lo anterior, nos parece conveniente, a nivel metodológico, mantener tal distinción para poder aislar las condiciones laborales impuestas a las mujeres que dependen de un empleador o de una empleadora en su desempeño laboral, de aquellas otras que de alguna forma viven en condiciones laborales "auto-impuestas", por ser empleadoras o bien por ser autoempleadas.

\subsection{Mujeres propietarias de microempresas}

Formalmente, las mujeres propietarias de una microempresa, en los términos definidos con anterioridad, representan la mayoría, tanto a nivel urbano como a nivel rural (ver el Cuadro 1).

Sin embargo, si analizamos con cuidado los datos disponibles nos daremos cuenta que las mujeres están al frente de unidades productivas definidas fundamentalmente por actividades de auto empleo o actividades por cuenta propia, las cuales se caracterizan por estar constituidas por una sola persona, responsable de realizar todas las actividades necesarias para el funcionamiento del negocio y por operar con bajos niveles de rentabilidad, lo cual proporciona a sus propietarios ingresos sumamente bajos, muchas veces por debajo del salario mínimo establecido oficialmente. Esta situación se revierte en el caso de las unidades microempresariales dirigidas por hombres.

\section{Cuadro 1}

Clasificación de la microempresa de acuerdo con el sexo del propietario (a) y la categoría ocupacional (En porcentajes)

\begin{tabular}{l|ccc}
\hline Area & Total & Hombres & Mujeres \\
\hline Urbana & 72.3 & 38.6 & 61.4 \\
Rural & 27.7 & 29.7 & 70.3 \\
Categoría & & & \\
Ocupacional & & & \\
Cuentas propias & 84.3 & 30.6 & 69.4 \\
Patronos & 15.7 & 66.2 & 33.8 \\
\hline
\end{tabular}

Fuente: Libro blanco de la microempresa, sobre la base de la Encuesta 123 de la Microempresa Salvadoreña, 1996.

Las mujeres dedicadas a actividades de auto empleo o de cuenta propia representan el 69.4 por ciento, del total de las mujeres que se encuentran al frente de un negocio dentro de la microempresa, lo cual reduce al 33.8 el porcentaje de mujeres que efectivamente pueden considerarse empleadoras, pues no sólo son propietarias de una microempresa, sino que contratan al menos a una persona para llevar a cabo las actividades relacionadas con la empresa. Los hombres, por su parte, presentan una tendencia opuesta ya que pueden considerase auto empleados únicamente el 30.6 por ciento de los microempresarios, lo cual deja, en consecuencia, que el 66.2 por ciento de los microempresarios pueda considerarse realmente como empleador.

2. Libro blanco de la microempresa, pp. 26-32. 
Esta primera conclusión que se puede extraer de los datos anteriores sobre la situación de la mujer en la microempresa, puede ser complementada con el análisis de los datos relacionados con las actividades empresariales a las que se dedican las mujeres en la microempresa así como con la lógica de reproducción que prevalece dentro de la actividad desarrollada en las microempresas, propie- dad de mujeres.

Por lo general, en el interior del sector informal puede observarse una tendencia al establecimiento de una división de las actividades empresariales entre hombres y mujeres, que se traduce a su vez en división entre sectores dinámicos y poco dinámicos asociada al género (ver los Cuadros 2 y 3 ).

\section{Cuadro 2}

Subsectores de la microempresa seleccionados de comercio, industria y servicios, por sexo del propietario

(En porcentajes)

\begin{tabular}{|c|c|c|c|}
\hline \multicolumn{2}{|c|}{ Sector } & \multirow[t]{2}{*}{ Hombres } & \multirow[t]{2}{*}{ Mujeres } \\
\hline 1. & Comercio & & \\
\hline 1.1. & Comercialización de granos básicos & 61 & 39 \\
\hline 1.2. & Venta de insumos agrícolas & 51 & 49 \\
\hline 1.3 & Compra-venta de alimentos y bebidas & 43 & 57 \\
\hline 1.4. & Compra-venta de ropa nueva & 41 & 59 \\
\hline 1.5. & Compra-venta de ropa usada & 45 & 55 \\
\hline 1.6. & Tienda & 44 & 56 \\
\hline 1.7. & Comedores & 26 & 74 \\
\hline 2. & Industria & & \\
\hline 2.1 . & Confección de ropa & 42 & 58 \\
\hline 2.2 . & Productos metálicos & 92 & 8 \\
\hline 2.3. & Carpintería y ebanistería & 92 & 8 \\
\hline 2.4. & Otros productos de madera & 96 & 4 \\
\hline 2.5 . & Bloques, ladrillos, tejas, etc & 85 & 15 \\
\hline 2.6. & Panadería, repostería & 38 & 62 \\
\hline 2.7. & Productos lácteos & 22 & 78 \\
\hline 2.8. & Otros alimentos y bebidas & 10 & 90 \\
\hline 2.9. & Productos de cuero & 81 & 19 \\
\hline 2.10 . & Artesanía decorativa & 31 & 69 \\
\hline 2.11. & Artesanía utilitaria & 50 & 50 \\
\hline 3. & Servicios & & \\
\hline 3.1. & Talleres de reparación eléctricos & 84 & 16 \\
\hline 3.2. & Reparación de automóviles y motos & 94 & 6 \\
\hline 3.3. & Reparaciones de calzado cuero & 88 & 12 \\
\hline 3.4. & Reparaciones otros & 77 & 23 \\
\hline 3.5 . & Lavandería y limpieza & 7 & 93 \\
\hline 3.6. & Barberías y salones de belleza & 25 & 75 \\
\hline 3.7. & Molinos de moler maíz & 49 & 51 \\
\hline
\end{tabular}

Fuente: Encuesta de la microempresa salvadoreña. Programa de fomento de la microemrpesa en las zonas marginales. Programa FOMMI, U.E-GOES/FIS, julio de 1995. 
La encuesta de la microempresa del programa FOMMI nos revela que las mujeres microempresarias, tanto las autoempleadas como las empleadoras, presentan una marcada tendencia a ubicarse en aclividades de comedores, producción de alimentos y bebidas, lavandería y limpieza, barberías y salones de belleza, talleres de confección de ropa, bazares y tiendas de consumo popular, que tradicionalmente son consideradas de "índole femenina". Los hombres, en cambio, tienden a situarse en actividades identificadas como "masculinas", tales como productos metálicos, carpintería y ebanistería, fabricación de bloques, ladrillos y tejas, talleres de reparación eléctrica, reparación de automóviles y motocicletas, construcción y transporte.

Esta división de actividades empresariales femeninas y masculinas, que caracteriza a la microempresa salvadoreña, guarda una alta correlación con la rentabilidad y los ingresos de los diferentes sectores y subsectores que la componen, dando paso así a una clara división entre sectores "diná- micos y poco dinámicos" que funciona en sentido opuesto a las actividades con mayor presencia de mujeres propietarias (ver el Cuadro 3). En efecto, los subsectores donde se identifica una mayor participación de mujeres microempresarias coinciden con los subsectores que tendencialmente tienen ganancias menores a la ganancia promedio del sector y donde el porcentaje de reducción de ventas es mayor o bien el porcentaje de aumento en las mismas es menor que el promedio.

Por el contrario, los indicadores tradicionales de éxito empresarial, tales como la capacidad de ahorro, el aumento de las ventas y ganancias, aplicados a la realidad de las microempresas, muestran un balance a favor de los establecimientos de propiedad masculina, reforzando con ello el mito dominante en nuestras sociedades acerca de que el espíritu empresarial es más fácilmente desarrollado por los hombres, quienes desde su infancia presentan una fuerte inclinación al riesgo, a la competencia y la innovación tecnológica.

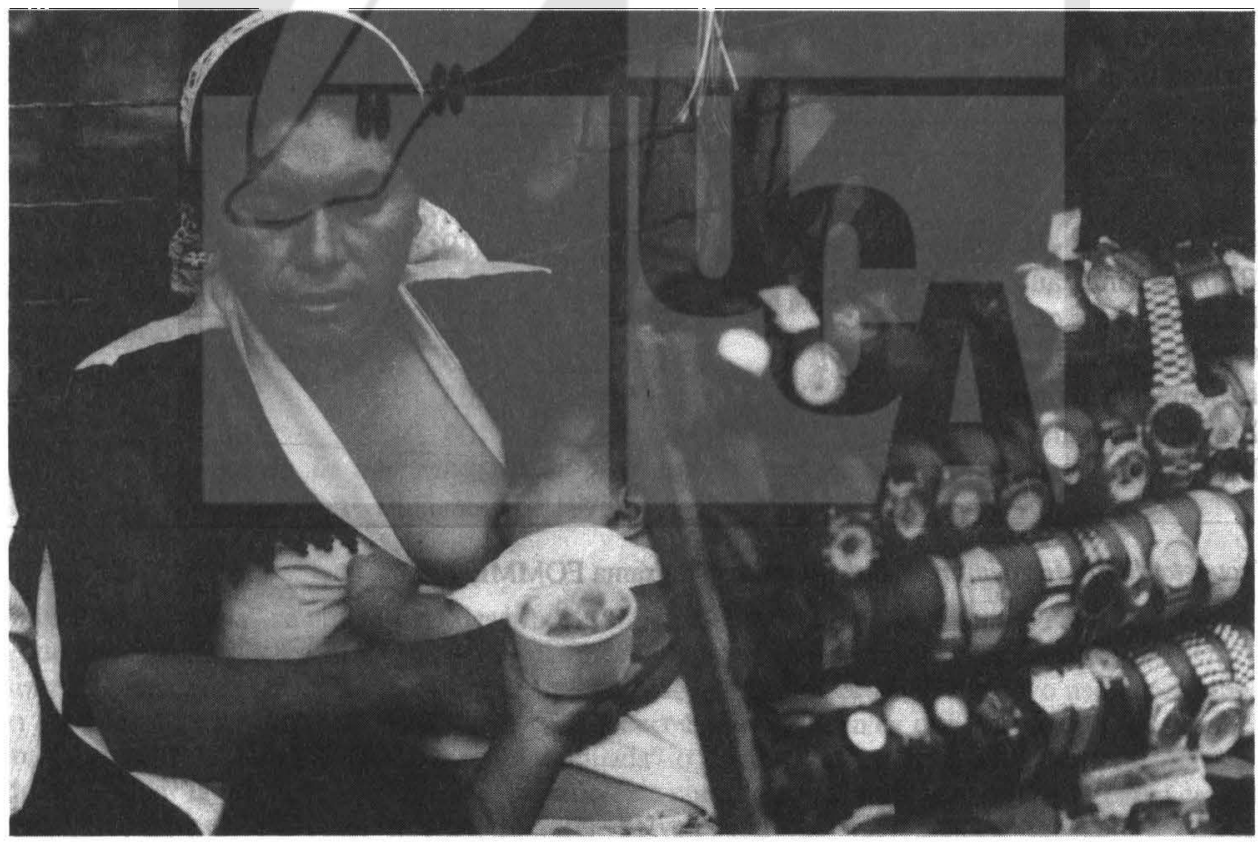




\section{Cuadro 3}

Indicadores de éxito potencial en algunos subsectores seleccionados de la microempresa (En porcentajes y colones)

\begin{tabular}{|c|c|c|c|c|}
\hline $\begin{array}{l}\text { Sectores y subsectores } \\
\text { seleccionados }\end{array}$ & $\begin{array}{l}\text { Porcentaje } \\
\text { con } \\
\text { capacidad de } \\
\text { ahorro }\end{array}$ & $\begin{array}{l}\text { Promedio de } \\
\text { ganancias } \\
\text { semanales } \\
\text { (colones) }\end{array}$ & $\begin{array}{l}\text { Porcentaje de } \\
\text { negocios con } \\
\text { incremento en } \\
\text { sus ventas }\end{array}$ & $\begin{array}{l}\text { Porcentaje de } \\
\text { negocios con } \\
\text { disminución } \\
\text { en sus ventas }\end{array}$ \\
\hline 1. Comercio & 39 & 529 & 12 & 42 \\
\hline 1.1. Granos Básicos & 40 & 640 & 10 & 42 \\
\hline 1.2. Insumos agrícolas & 35 & 537 & 14 & 54 \\
\hline 1.3. Alimentos y bebidas & 43 & 487 & 9 & 47 \\
\hline 1.4. Ropa nueva & 46 & 424 & 15 & 38 \\
\hline 1.5. Ropa usada & 39 & 410 & 20 & 42 \\
\hline 1.6. Tienda & 33 & 534 & 11 & 39 \\
\hline 1.7. Comedores & 36 & 566 & 14 & 45 \\
\hline 2. Industria & 41 & 539 & 16 & 51 \\
\hline 2.1. Sastrería & 38 & 369 & 17 & 55 \\
\hline 2.2. Productos metálicos & 56 & 755 & 20 & $\begin{array}{l}32 \\
55\end{array}$ \\
\hline 2.3. Carpintería, ebanistería & 39 & 731 & 16 & 50 \\
\hline 2.4. Otros productos metálicos & 39 & 815 & 14 & 54 \\
\hline 2.5. Bloques, ladrillos, tejas & 45 & 839 & 21 & 45 \\
\hline 2.6. Panadería, repostería & 49 & 663 & 18 & 54 \\
\hline 2.7. Productos lácteos & 59 & 736 & 15 & 65 \\
\hline 2.8. Otros alimentos, bebidas & 278 & 373 & 13 & 48 \\
\hline 2.9. Productos de cuero & 37 & 746 & 15 & 36 \\
\hline 2.10. Artesanía decorativa & 45 & 464 & 12 & 31 \\
\hline 2.11. Artesanía utilitaria & 36 & 444 & 13 & 53 \\
\hline 3. Servicios & 40 & 412 & 15 & 51 \\
\hline 3.1. Reparaciones eléctricas & 42 & 519 & 16 & 47 \\
\hline 3.2. Reparaciones autos de motos & 54 & 591 & 22 & 47 \\
\hline 3.3. Reparaciones calzado y cuero & 30 & 292 & 11 & 52 \\
\hline 3.4. Otras reparaciones & 41 & 465 & 12 & 51 \\
\hline 3.5. Lavandería y limpieza & 15 & 205 & 6 & 66 \\
\hline 3.6. Barberías y salas de belleza & 41 & 404 & 17 & 50 \\
\hline 3.7. Molinos de moler maíz & 38 & 383 & 12 & 62 \\
\hline
\end{tabular}

Fuente: Encuesta de la Microempresa Salvadoreña. Programa FOMMI, 1995. 
Los datos anteriores explican, en gran medida, el hecho de que las microempresas propiedad de mujeres representen el 70 por ciento de las microempresas ubicadas en el segmento de subsistencia, el 53 por ciento de las microempresas en situación de reproducción simple y únicamente el 25 por ciento de las microempresas en el segmento de reproducción ampliada. (Ver el Cuadro 4). También nos indican que no es una simple casualidad que las microempresas propiedad de hombres registren una tendencia diametralmente opuesta: son apenas el 30 por ciento de las microempresas de subsistencia, el 46 por ciento de las microempresas de reproducción simple y el 75 por ciento de las microempresas situadas en el segmento de reproducción ampliada. ${ }^{3}$

El resultado de todo lo anterior se resume en un hecho simple, pero de graves implicaciones en têrminos de equidad y de posibilidades reales para el desarrollo socioeconómico para el país, las mujeres propietarias de este sector, tanto empleadores como auto empleadas, perciben ingresos mensuales promedios menores que los hombres en esa misma clasificación ocupacional (ver el Cuadro 5).

\section{Cuadro 4}

División de las microempresas en segmentos productivos, según sexo del propietario (a) (1996)

(En porcentajes)

\begin{tabular}{lcc} 
Segmento productivo & Hombres & Mujeres \\
\hline Microempresas de subsistencia & 29.8 & 70.2 \\
Microempresas de reproducción simple & 47.0 & 53.0 \\
Microempresas de reproducción ampliada & 75.0 & 25.0 \\
\hline
\end{tabular}

Fuente: Libro blanco de la microempresa, sobre la base de la Encuesta 123 de la microempresa salvadoreña, 1996.

\section{Cuadro 5}

Microempresas según tramo de ganancia mensual y según sexo (En porcentajes)

\begin{tabular}{|c|c|c|c|}
\hline $\begin{array}{l}\text { Tramo de ingreso } \\
\text { mensual } \\
\text { (En colones) }\end{array}$ & Total & Hombres & Mujeres \\
\hline De 1 a 500 & 6.7 & 2.4 & 8.4 \\
\hline De 501 a 999 & 10.0 & 5.0 & 12.0 \\
\hline De 1,000 a 1,999 & 20.7 & 16.6 & 22.3 \\
\hline De 2,000 a 4,999 & 36.6 & 41.5 & 34.7 \\
\hline De 5,000 a 9,999 & 15.0 & 21.9 & 12.3 \\
\hline De 10,000 a 14,999 & 5.5 & 4.4 & 6.0 \\
\hline Más de 15,000 & 5.4 & 8.1 & 4.4 \\
\hline
\end{tabular}

Fuente: Estudio nacional de la demanda de crédito para la microempresa. Proyecto MIP: CAM-CRSFINCA-FOMMI-OEF-SNF. Diciembre de 1996.

3. El término "subsistencia" se utiliza para describir las microempresas que presentan niveles tan bajos de productividad que sólo logran generar ingresos para satisfacer el consumo inmediato de sus propietarios(as); "reproducción simple" hace referencia a las microempresas que poseen recursos productivos cuyo uso genera ingresos que cubren los costos de su actividad, pero sin alcanzar excedentes suficientes que permitan la inversión en crecimiento; finalmente, el término "reproducción ampliada" o "micro top", describe a las microempresas que han logrado desarrollar la productividad de manera suficiente como para permitir la reinversión del excedente económico en el crecimiento de la empresa y que se desenvuelven dentro de una lógica capitalista. 


\subsection{Mujeres empleadas en microempresas}

En términos generales, la situación de las mujeres empleadas en la microempresa presenta los mismos niveles de precariedad que la de los hombres, pudiéndose distinguir, sin embargo, ciertas particularidades que agudizan en ellas esta situación, especialmente dados los altos índices de jefatura femenina que prevalecen en este sector.

En primer lugar, el fenómeno de trabajo no remunerado suele asociarse al sector de la microempresa en general. Los datos disponibles mues- tran evidencias de la posibilidad de que la mayor incidencia de este fenómeno se presente en las mujeres, especialmente en el sector comercio, donde existe una mayor participación de mujeres (ver el Cuadro 6). Esta categoría ocupacional excluye a las aprendices y hace referencia a mujeres que pueden estar laborando de manera parcial o total una determinada jornada de trabajo, sin que por ello reciban una compensación en términos monetarios, en virtud de determinados lazos de parentesco, amistad o afinidad que pueda tener con el o la propietaria de la microempresa.

\section{Cuadro 6}

Empleo en las microempresas, por sector, remuneración y sexo (En porcentajes)

\begin{tabular}{lcccc}
\hline Sector & $\begin{array}{c}\text { Hombres } \\
\text { remunerados }\end{array}$ & $\begin{array}{c}\text { Mujeres } \\
\text { remuneradas }\end{array}$ & $\begin{array}{c}\text { Hombres } \\
\text { no remuerados }\end{array}$ & $\begin{array}{c}\text { Mujeres } \\
\text { no remuneradas }\left(^{*}\right)\end{array}$ \\
\hline Comercio & 17.57 & 32.46 & 15.36 & 30.13 \\
Industria & 50.12 & 20.52 & 8.5 & 10.56 \\
Servicios & 47.75 & 22.17 & 8.73 & 8.07 \\
Otros & 63.52 & 5.09 & 18.15 & 6.76 \\
\hline
\end{tabular}

(*) La diferencia entre la suma de las cuatro columnas y el total corresponde al porcentaje de aprendices empleados en los diferentes sectores, dato que no se incluye por no estar disponible de forma desagregada por sexo.

Fuente: Encuesta de la microempresa salvadoreña. Programa FOMMI, 1995.

Otro elemento importante para medir las condiciones de mayor desigualdad que enfrentan las mujeres empleadas del sector de la microempresa nos lo proporciona la información sobre remuneraciones promedio mensuales, la cual no obstante se encuentra disponible para las empresas de uno a cuatro trabajadores (as), creemos que nos acerca de manera confiable al universo de la microempresa (ver el Cuadro 7). Los datos del Cuadro 7 , si bien reflejan una situación insatisfactoria para los hombres y mujeres con empleo remunerado en la microempresa, ya que en ambos casos perciben ingresos insuficientes para satisfacer las necesida- des básicas de las familias que dependen de él o de ella y para su reproducción material y espiritual, no por ello nos impiden percatarnos de la mayor desigualdad que representan estos niveles salariales para las mujeres. En efecto, en los cuatro años considerados y sin excepción se presenta una marcada tendencia a mantener los salarios de las mujeres por debajo de los niveles salariales de los hombres, con el agravante de que esta disparidad salarial tiende a acentuarse en los últimos años del período, coincidiendo con la profundización del proceso de ajuste estructural de la economía salvadoreña. 


\section{Cuadro 7}

Remuneraciones mensuales medias de la población ocupada en el sector informal en establecimientos con uno a cuatro trabajadores (as), por sexo y año

(En colones)

\begin{tabular}{lcccc}
\hline Ocupados (as) & $1988 / 89$ & $1990 / 91$ & $1992 / 93$ & 1994 \\
\hline Total & 662.5 & 835.2 & 1119.1 & 1425.3 \\
Hombres & 706.9 & 863.1 & 1237.6 & 1585.7 \\
Mujeres & 568.8 & 773.0 & 653.6 & 1147.3 \\
\hline
\end{tabular}

Fuente: Carlos, Briones. ¿Continuidad o transformación? El sector informal urbano 1988-1994. FLACSO, 1995. Sobre la base de las Encuestas de Hogares de Propósitos Múltiples del Ministerio de Relaciones Exteriores.

Un tercer indicador del cual podemos auxiliarnos para describir la situación laboral de las mujeres empleadas en el sector de la microempresa lo constituye el acceso a un sistema de seguridad social que provea a las mujeres y sus familias de una red de servicios de salud y protección en casos de incapacidad, vejez y muerte, que contribuya a un mejoramiento en la calidad de vida.

El sistema de seguridad social en El Salvador tiene una cobertura sumamente baja, lo cual es válido tanto para los trabajadores (as) del sector informal como para los del sector formal, donde la cobertura no alcanza ni tan siquiera al 25 por ciento de la PEA ocupada. En el sector informal la cobertura apenas era del 3 por ciento para el año 1992. Las disparidades entre hombres y mujeres son menos acentuadas que en los indicadores señalados anteriormente; manteniéndose, sin embargo, una tendencia a una menor cobertura en las mujeres (ver el Cuadro 8).

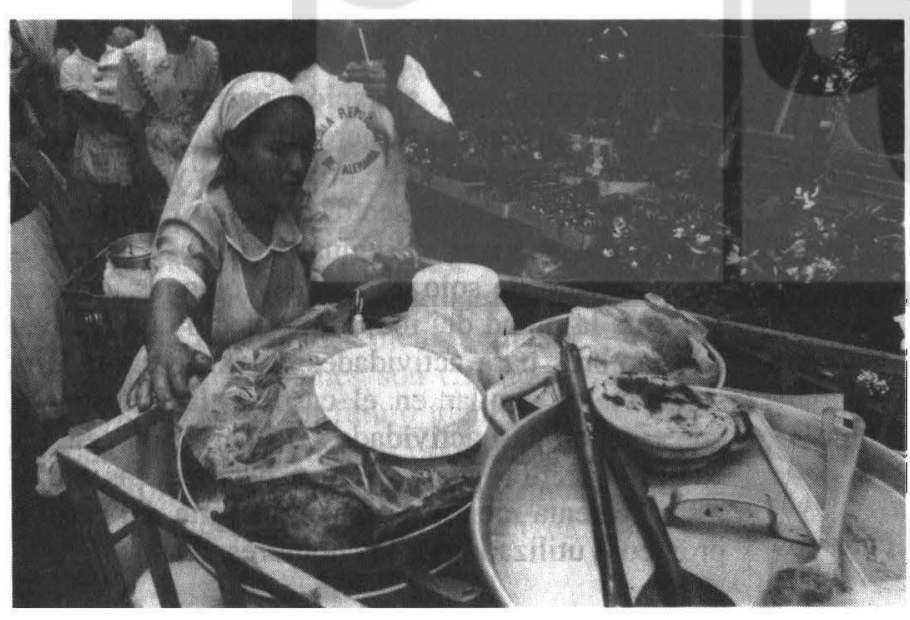

Cuadro 8

Cobertura del sistema de seguridad social de los ocupados (as) del sector informal urbano, según sexo y años

(En porcentajes)

\begin{tabular}{llll}
\hline Población cubierta & 1990 & 1991 & 1992 \\
\hline Total & 2.46 & 3.21 & 3.10 \\
Hombres & 3.06 & 4.02 & 3.61 \\
Mujeres & 1.86 & 2.42 & 2.61 \\
\hline
\end{tabular}

Fuente: Edy Arelí Ortiz Cañas, Mujeres del sector informal urbano en El Salvador. Serie Estudios de la Mujer, No 3, Instituto de Investigación, Capacitación y Desarrollo de la Mujer (IMU), junio de 1994.

3. Determinantes de la situación laboral de la mujer en la microempresa

Sin agotar toda la problemática del desarrollo de la mujer ocupada en la microempresa, los principales determinantes de su realidad laboral en este sector pueden ser agrupados en las siguientes categorías.

\subsection{Problemas relacionados con la doble jornada de trabajo}

Las mujeres de este sector en general no cuentan con apoyo para la realización del trabajo doméstico, el cual se ven obligadas a llevar a cabo antes y después del trabajo normal de la empresa. Tampoco cuentan con ayuda para suplir las tareas de cuido de niños y ni- 
ñas, por lo que muchas veces se ven en la necesidad de dedicar menos horas diarias a la empresa o de situar el negocio en el mismo lugar de vivien$\mathrm{da}$, a fin de poder compatibilizar las labores reproductivas de la familia con el desempeño de una actividad'económicamente productiva, lo cual las limita en sus posibilidades de desarrollo empresarial.

Tal como lo indican los datos del Cuadro 9, este problema no es compartido por los hombres de la microempresa, quienes en caso de tener que desempeñar una tarea suplementaria a la actividad microempresarial lo hacen dedicándose a actividades también de índole productiva, tales como la agricultura, por las cuales, en general, esperan percibir ingresos monetarios.

Cuadro 9

Actividades suplementarias de los propietarios (as) en la microempresa (En porcentajes)

Actividades adicionales a la de la microempresa Hombres Mujeres

\begin{tabular}{lrr}
\hline Sin otra actividad & 80 & 40 \\
Agricultura & 6 & 2 \\
Empleo asalariado & 2 & 2 \\
Tareas domésticas & 3 & 42 \\
Otras & 9 & 4 \\
\hline
\end{tabular}

Fuente: Encuesta de la microempresa salvadoreña. Programa FOMMI, 1995.

\subsection{Problemas relacionados con el acceso al crédito}

Adicionalmente a los problemas de condiciones y metodologías de crédito, comunes a hombres y mujeres del sector de la microempresa, las microempresarias se enfrentan a obstáculos adicionales para obtener financiamiento para sus actividades, derivados de problemas de género, entre los cuales pueden mencionarse los siguientes.
Las actividades desarrolladas mayoritariamente por las mujeres microempresarias, tales como comercio minorista y ambulante, costura, preparación de comidas y limpieza de ropa, representan a sectores menos dinámicos y con una demanda sobresaturada, lo cual hace que sean menos atractivas como sujetos de crédito del sistema financiero formal y de otros programas de crédito. En general, esta situación provoca que las mujeres tengan acceso a niveles de financiamiento muy bajos y en condiciones sumamente desfavorables, lo que a su vez las mantiene en situación de subsistencia.

Las limitaciones de tiempo que las mujeres tienen para dedicarse exclusivamente a su empresa y el exceso de responsabilidades a nivel familiar, especial. mente en el caso de mujeres jefes de hogar, las vuelve sujetos de alto riesgo para las instituciones financieras y los programas de crédito.

Las mujeres tienen menos posibilidad para cumplir con las garantías reales exigidas por las entidades financieras, ya que, por lo general, no son propietarias ni tienen amistades asalariadas que puedan servir cono fiadores o codeudores solidarios de los créditos que solicitan. Estos factores provocan, en la mayoría de casos, una demanda insatisfecha de crédito mayor en relación con la que presentan los hombres, así como la otorgación de montos de créditos en promedio muy por debajo de los montos otorgados a los hombres (ver el Cuadro 10) .

Respecto a esta situación particular vale la pena destacar que las mujeres demandan y reciben globalmente un monto de crédito dos veces mayor que los hombres en el sector comercio, donde son la mayoría. A nivel individual hacen uso de créditos promedio de solo $13,5553.47$ colones, que representa la mitad del monto promedio que reciben los hombres para actividades en este sector. Esta situación es similar en el caso de la industria y empeora en las actividades de servicios, en las cuales el crédito promedio que perciben las mujeres representa menos de la cuarta parte del crédito promedio utilizado por los hombres. 


\section{Cuadro 10}

Monto de crédito solicitado y aprobado por las microempresas a nivel nacional, por rama de actividad económica y según sexo del propietario (a)

(En colones)

\begin{tabular}{lrrc}
\hline Rama de actividad & Crédito solicitado & Crédito aprobado & $\begin{array}{c}\text { Monto promedio } \\
\text { de crédito }\end{array}$ \\
\hline Comercio & $177,745,300$ & $158,295,820$ & $16,377.08$ \\
Hombres & $59,804,600$ & $52,869,600$ & $28,953.00$ \\
Mujeres & $117,940,700$ & $105,426,220$ & $13,553.47$ \\
& & & \\
Industria & $32,209,800$ & $26,202,800$ & $27,398.32$ \\
Hombres & $21,403,00$ & $17,916,00$ & $34,505.83$ \\
Mujeres & $10,806,800$ & $8,286,800$ & $16,737.06$ \\
& & & \\
Servicios & $26,811,900$ & $19,048,140$ & $21,022.40$ \\
Hombres & $17,972,000$ & $10,764,240$ & $38,702.44$ \\
Mujeres & $8,839,900$ & $8,283,900$ & $9,182.12$ \\
\hline
\end{tabular}

Fuente: Estudio nacional de la demanda de crédito a la microempresa. Proyecto MIP: CAM-CRSFINCA-FOMMI-OEF-SNF. Diciembre de 1996.

\subsection{Problemas relacionados con el diseño de los programas de capacitación y de asistencia técnica}

Los programas de capacitación y asistencia técnica, por lo general, no se adaptan a las necesidades prácticas y a la escala de operación de las microempresas de mujeres, y también por regla general utilizan un lenguaje y una metodología poco accesibles o motivadoras para las mujeres.

La principal limitante en esta área la constituyen los altos índices de analfabetismo y los bajos niveles de escolaridad que presentan las mujeres microempresarias (ver el Cuadro 11), que a su vez son resultante de la división de funciones que socialmente se asigna a hombres y mujeres. En la práctica, esa división opera dentro de las familias dando una menor educación a las hijas, quienes son condicionadas para tener en el futuro menor capacidad para aprovechar las oportunidades de formación que eventualmente puedan encontrarse disponibles en el mercado.
Enfocado desde esta perspectiva, para las mujeres microempresarias, el dilema frente a la capacitación y la asistencia técnica no se circunscribe únicamente en torno al costo monetario de esa formación, sino que trasciende al ámbito de la adquisición de los conocimientos y las habilidades previas que les permitan aprovechar, en igualdad de condiciones con los hombres, la capacitación y la asistencia técnica que las diversas instituciones públicas y privadas ponen a disposición del sector

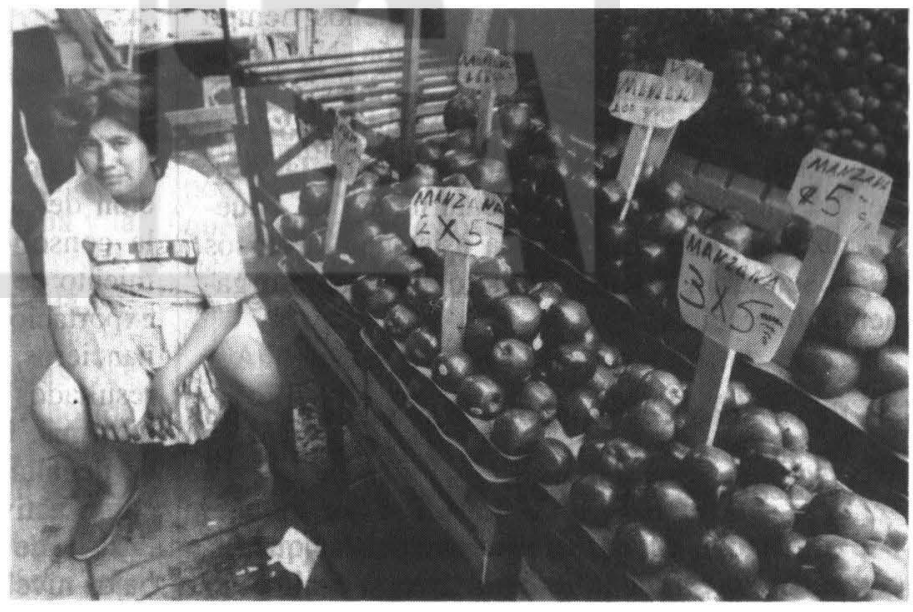


de la microempresa, sin hacer ninguna distinción con base en el género.

\section{Cuadro 11}

Nivel educativo de los propietarios (as) de microempresas

(En porcentajes)

\begin{tabular}{lrcc}
\hline $\begin{array}{l}\text { Ultimo grado } \\
\text { aprobado }\end{array}$ & Total & Mujeres & Hombres \\
\hline Ninguno & 9.6 & 11.6 & 5.9 \\
Primer ciclo & 12.7 & 14.7 & 9.0 \\
Segundo ciclo & 3.0 & 30.8 & 28.5 \\
Tercer ciclo & 21.3 & 19.1 & 25.5 \\
$\begin{array}{l}\text { Bachillerato } \\
\text { Estudios técnicos }\end{array}$ & 20.4 & 18.6 & 23.7 \\
$\begin{array}{l}\text { Estudios } \\
\text { universitarios }\end{array}$ & 2.1 & 0.2 & 0.0 \\
$\begin{array}{l}\text { Técnico } \\
\text { graduado }\end{array}$ & 2.0 & 2.4 & 3.5 \\
$\begin{array}{l}\text { Profesional } \\
\text { graduado }\end{array}$ & 0.9 & 0.5 & 1.7 \\
\hline
\end{tabular}

Fuente: Estudio nacional de la demanda de crédito en la microempresa. Proyecto MIP: CAM-CRS-FINCAFOMMI-OEF-SNF. Diciembre de 1996.

Por otro lado, también estos programas presentan un sesgo a favor de las microempresas de los sectores de producción y servicios más dinámicos , ubicadas en los segmentos de reproducción simple y micro Top, en los cuales las mujeres no tienen una participación significativa.

Adicionalmente, por las responsabilidades domésticas, las mujeres disponen de menos tiempo para asistir a los cursos de capacitación. No tienen apoyo para el cuidado de niños y niñas cuando asisten a dichos cursos de capacitación: lo cual agrava aun mas el problema de acceso de las mujeres al financiamiento, particularmente en aquellos casos en que se define la asistencia a cursos de capacitación como requisito para el otorgamiento de créditos.

\subsection{Problemas relacionados con el desarrollo de actitudes empresariales favorables al aumento de la competitividad}

El desarrollo de actitudes empresariales que favorezcan el crecimiento cuantitativo y cualitativo de las microempresas y el traslado a subsectores más dinámicos, desde el punto de la rentabilidad, se presenta con mayor dificultad en el caso de las microempresarias, por las razones siguientes.

Las mujeres microempresarias encuentran dificultades culturales y sociales para abandonar el rol tradicional que se le asigna a la mujer dentro del hogar y la familia. Por regla general, el desempeño de su actividad empresarial no se enfoca como una opción de superación personal, sino como una actividad complementaria o sustituta de los ingresos, que proveen los esposos o compañeros de vida. Esta percepción limita el grado de compromiso que las microempresarias tienen con sus negocios y su capacidad de innovación presente y futura.

El nivel de autoestima de las mujeres microempresarias se encuentra normalmente deteriorado debido a una serie de factores asociados a la violencia doméstica, al abandono, a la sobrecarga de responsabilidades familiares, entre otros. Este elemento determina conductas extremadamente pasivas o pesimistas frente al desarrollo de las empresas, que les impide tomar riesgos o aprovechar de manera oportuna las posibilidades que los programas y proyectos ofrecen para mejorar la situación de su negocio.

El riesgo y la ambición dentro de la sociedad tradicionalmente son características definidas para los hombres, mientras que a la mujer se le inculca la búsqueda de seguridad y el conformismo. Este elemento cultural marca de manera significativa la distinta actitud frente al mercado y la competencia, que potencialmente podrían desarrollar hombres y mujeres del sector de la microempresa.

\section{Necesidad de una política laboral específica para el sector informal con enfoque de géne- ro}

La profundización del proceso de reestructuración del aparato productivo nacional, orientado a la consolidación de un nuevo modelo de crecimiento de la economía salvadoreña, basada en las exportaciones y en los sectores comerciales y financieros, ha tenido como uno de sus principales resultados la ampliación del empleo en el sector informal. Entendido este sector no como sinónimo de ilegalidad o falta de registros, sino básicamente como actividades de comercio, servicios y de industria de baja productividad, las cuales generan bajos niveles de rentabilidad e ingresos. 
Este fenómeno no puede analizarse como un "accidente" del programa de ajuste estructural, sino que, por el contrario, constituye un efecto lógico y necesario para el éxito del nuevo modelo de crecimiento de la economía y, por tanto, es congruente con su lógica de funcionamiento. El programa de ajuste estructural no ha tenido ni tendrá como consecuencia la disminución del sector informal a través de la destrucción de las unidades microempresariales o del autoempleo que se desarrolla dentro de él. Lo que si está generando es una mayor precariedad de los empleos y los ingresos de los trabajadores y trabajadoras de este sector, al mismo liempo que los propietarios y propietarias dismimuyen sus niveles de rentabilidad y sus perspectivas de desarrollo empresarial se ven frustradas.

Las medidas de ajuste estructural, tales como la privatización del sistema financiero, la apertura externa indiscriminada y la reforma del sistema tributario, han producido para las empresas del sector formal, especialmente pequeñas y medianas, un aumento significativo en sus costos, lo que a su vez, aunado a la perdida progresiva de la capacidad adquisitiva de la población, les ha imposibilitado a muchas de estas empresas continuar operando en sus mercados tradicionales, y han optado por el cierre definitivo o el cambio a una actividad de menores costos de permanencia y salida.

Estas reestructuraciones "normales" dentro de la lógica del ajuste estructural tienen como contrapartida una pérdida de empleos permanentes y un aumento en las actividades y personas que se desempeñan en el llamado sector informal, lo cual conlleva una sobresaturación de estas actividades, disminución de las ganancias promedio y desmembramiento de las condiciones laborales para los trabajadores y las trabajadoras del sector informal.

De no modificarse substancialmente la dinámica de crecimiento de la economía salvadoreña y la política económica que la sustenta, en los próximos años, más de las dos terceras partes de la población económicamente activa ocupada se encontrara en el sector informal, con todas las implicaciones que esto representará en términos de deterioro en la calidad del empleo y en las condiciones de vida de las familias ligadas a este sector.

En este marco, la política laboral del país, si quiere ser realmente una política de carácter na- cional, no podrá continuar siendo una política exclusiva para los trabajadores y trabajadoras del sector formal, sino que deberá incorporar medidas y acciones orientadas a garantizar condiciones mínimas de bienestar para los ocupados (as) del sector informal. Por supuesto, esto implica una voluntad política para mejorar las condiciones laborales de la población, es decir, esta tarea no se le deja al mercado.

Pero adicionalmente, no basta con que la política laboral tome en consideración al sector informal como sujeto, sino que es necesario que ésta asuma en su diseño y aplicación una auténtica perspectiva de género, en el sentido de garantizar, a través de medidas específicas, que las mujeres tengan iguales oportunidades que los hombres para mejorar sus condiciones laborales.

Algunas medidas a ser consideradas en el diseño e implantación de una política laboral con estas características podrían ser las siguientes.

El fomento de la organización gremial de los ocupados y ocupadas en el sector de la microempresa, tanto a nivel de los propietarios (as) como de los empleados (as), a nivel geográfico y por rama de actividad económica, como el mejor instrumento para mejorar el acceso de los ocupados (as) de este sector a mejores condiciones laborales.

Funcionamiento de un régimen fiscal transitorio para el sector de la microempresa que estimule el mejoramiento de la calidad del empleo permanente y temporal en las empresas de este sector y defina de manera clara y precisa incentivos para las microempresas que remuneran los trabajadores y trabajadoras al nivel del salario mínimo o por encima de él. Dado que la contratación de trabajadoras y trabajadores se presenta sobre todo en los segmentos de reproducción simple y de reproducción ampliada, la aplicación de estos incentivos podría focalizarse en las unidades empresariales que conforman estos segmentos, evitando aś los riesgos que conlleva una aplicación indiscriminada.

Apoyo del Estado al funcionamiento de sistemas privados de seguridad social, administrados por las organizaciones gremiales de la microempresa. El apoyo del Estado a estos sistemas debería abarcar al menos las siguientes áreas: financiamiento de estudios técnicos para determinar los sistemas de seguridad social que más se adaptan a 
las necesidades y características de los diferentes segmentos productivos que componen la microempresa; asesorar a las organizaciones gremiales de la microempresa sobre alternativas viables para poner en marcha sistemas de seguridad social para sus miembros, sean éstos propietarios (as) o empleados (as); promover activamente la incoporación de mujeres y sus necesidades específicas en los sistemas de seguridad social de la microempresa , y subsidiar de manera focalizada los sistemas de seguridad social de los segmentos de subsistencia, principalmente en los que se dé cobertura a mujeres jefes de hogar.

Incorporación dentro del Sistema Nacional de Formación Profesional que dirige el INSAFORP acciones concretas para asegurar a las mujeres ocupadas en la microempresa el acceso al entrenamiento previo que requieren para aprovechar las oportunidades de capacitación y asistencia técnica disponibles en el mercado, así como la adaptación de los contenidos y las metodologías de estos cursos a la realidad y las características particulares de las empresarias y empleadas.

Creación y mantenimiento de una red nacional de guarderías y centros de desarrollo infantil para uso de propietarias y empleadas del sector de la microempresa, que enfatice la atención de los hijos e hijas de las ocupadas en los segmentos de subsistencia y adapte las características de la jornada de trabajo en este sector.

Ejecución de una campaña a nivel nacional para informar y sensibilizar a la opinión pública sobre la necesidad de garantizar los derechos de los trabajadores y las trabajadoras del sector informal y avanzar hacia un tratamiento equitativo entre hombres y mujeres, ocupados en este sector, en términos de oportunidades de empleo y remuneraciones.

Capacitación de funcionarios y funcionarias responsables de la formulación y ejecución de políticas laborales para el sector formal e informal sobre el enfoque de género y las metodologías de trabajo que promueven la utilización de este enfoque en las prácticas cotidianas del quehacer de las instituciones.

Diseñar y poner en marcha un sistema permanente de monitoreo y evaluación sobre los avances obtenidos en materia de derechos laborales en el sector informal y divulgar los resultados entre las instituciones públicas y privadas relacionadas con el tema.

Promover junto con los organismos privados de desarrollo y las agencias de cooperación externa, el financiamiento de proyectos productivos de mujeres en actividades no tradicionales y la divulgación amplia de sus resultados, a fin de que puedan convertirse en modelos ejemplarizantes para las mujeres.

Promover ante los organismos públicos y privados que financian y ejecutan programas de capacitación y asesoría para los microempresarios y microempresarias, la incorporación obligatoria en estos programas de contenidos de autoestima, liderazgo y formación de actitudes favorables al crecimiento empresarial de las mujeres.

Introducir dentro de la agenda del Consejo Superior del Trabajo el tema de las condiciones laborales en el sector informal y la búsqueda de equidad entre hombres y mujeres ocupados en este sector y asegurar recursos para la investigación y el diseño de recomendaciones de política sobre estos temas.

Crear una red de cooperación interinstitucional dirigida por el Ministerio de Trabajo que coordine un uso eficiente de los recursos disponibles a nivel público y privado, que puedan contribuir al logro de los objetivos y metas de la política laboral para el sector informal. 